\title{
Psychopaths, Ill-Will, and the Wrong-Making Features of Actions
}

\author{
SEAN CLANCY \\ Syracuse University
}

\begin{abstract}
Many recent discussions of psychopaths have centered on the question of whether they can express ill-will when they act, a capacity which is generally taken to be required for moral blameworthiness. However, the debate over ill-will currently stands at an impasse; the participants are in substantial agreement as to which attitudes psychopaths can express, but disagree as to which attitudes count as ill-will. I argue that this impasse reflects an underlying, implicit disagreement as to which features of actions are wrong-making. By uncovering this implicit disagreement and addressing it head-on, we should be able to break the impasse.
\end{abstract}

\section{Introduction}

Are psychopaths morally blameworthy for their bad actions? Many recent treatments of this question have focused on psychopaths' capacity, or lack thereof, to express ill-will by acting. Psychopaths apparently understand that others can be harmed, and thus their actions can express the judgment that the harm they inflict on others is unimportant. But psychopaths apparently do not understand that others have moral standing, and thus their actions cannot express contempt for other persons qua moral patients. While the parties to the ill-will debate agree as to which attitudes psychopaths can express, they disagree as to which attitudes count as ill-will. The debate seems to have reached an impasse.

I argue here that this impasse is due in large part to an implicit disagreement as to which features of actions are wrong-making. Ill-will is best understood, I contend, as an objectionable attitude towards one or more of the features of actions which make them wrong. As I hope to show, the question of precisely which features make actions wrong is more difficult than has previously been appreciated. Even when a given set of normative assumptions is shared, it is

Contact: Sean Clancy <clancy.philosophy@gmail.com> 
possible for different parties to reasonably identify different features of an action as wrong-making.

This, I contend, is a major cause of the disagreement over the ill-will question. The expression of ill-will requires awareness of the wrong-making features, and psychopaths are aware of some features but not others. Some parties implicitly identify the wrong-making features as those of which the psychopath is aware-such as the harmfulness of his actions-and conclude that he does express ill-will. Others implicitly identify the wrong-making features as those of which the psychopath is not aware-such as the fact that he harms persons with moral standing - and conclude that he does not express ill-will. This underlying disagreement explains why the ill-will question has reached its current impasse; exposing the disagreement reveals a way in which the impasse can be broken.

In Section 2, I provide an overview of the ill-will question and the surrounding impasse. In Section 3, I offer my diagnosis - our disagreement about whether psychopaths can express ill-will reflects an underlying disagreement as to which features of actions are wrong-making. In Section 4, I discuss the prospects for resolving this underlying disagreement and breaking the impasse.

\section{Psychopaths and Ill-Will}

The empirical details of psychopathy are the subject of active investigation both by psychologists and by philosophers. ${ }^{1}$ But many of the philosophical debates surrounding psychopathy -including those surrounding the ill-will questionare divorced from open empirical questions, relying on characterizations of the condition that are either abstracted away from the empirical details or stipulative in nature. Matthew Talbert (2008: 518), for instance, relies on a stipulative account of psychopaths as agents who are "blind" to moral considerations but otherwise cognitively normal. ${ }^{2}$ Real-life psychopaths are not quite cognitively normal even outside of moral domains, ${ }^{3}$ and there is a question as to whether their moral blindness is complete or partial, ${ }^{4}$ but these details will not make a significant difference to the following discussion. I therefore assume Talbert's characterization of psychopathy for the remainder.

Most commentators, both inside and outside the debate over psychopathy,

1. See Cleckley (1964), Hare (1993), Lykken (2006), Widiger (2006), Kiehl (2008), and Scott (2014) for general descriptions of the condition.

2. Nelkin (2015) appeals to Talbert's stipulative characterization, and I understand the other authors discussed here to employ substantially similar accounts of the condition.

3. See, e.g. Litton (2008) for discussion of the impulse-control problems associated with psychopathy, which lead to behavior that is not only immoral but imprudent.

4. See, e.g., Maibom (2008), Borg and Sinnott-Armstrong (2013). 
agree that wrongdoing is not itself sufficient to ground moral blameworthiness. Typically, blameworthiness requires that an action reflect ill-will on the part of the agent performing it. ${ }^{5}$ As we will see, the question of precisely what ill-will consists in is a complicated one, but we can characterize ill-will informally by appealing to cases in which it intuitively seems to be absent. Sometimes agents are excused from blame on the grounds that they "meant well", or, at least, that they did not mean badly. The gregarious host who poisons his guest inadvertently, because the sugar in his cupboard has been secretly replaced with arsenic, lacks ill-will; arguably, so does the small child who kills his younger brother but who does not have a good understanding of what death is. What is absent in these cases is a kind of malice, or contempt for the victim, or wicked intent; in short, the agents do not express any of the bad attitudes that seem to be required to ground blameworthiness. ${ }^{6}$ When we evaluate psychopaths for ill-will, we are asking whether they possess bad attitudes of the relevant kind and express them by acting.

Talbert $(2008 ; 2012 ; 2014)$ argues that psychopaths can express such attitudes. While they may be blind to moral considerations, psychopaths have a good understanding of the psychology of other humans. They understand that others have mental lives much like their own, and in particular that others can feel pain and have their preferences frustrated. They therefore understand that others can be harmed. Because psychopaths understand harm, they can intend to harm others when they act; by so intending, they demonstrate that they judge that the harmfulness of an action does not constitute a reason to refrain from performing it. This judgment, according to Talbert, represents a kind of malice or contempt towards others, which is sufficient for ill-will; thus psychopaths satisfy this requirement for blameworthiness.

Neil Levy (2007), David Shoemaker (2011), and Dana Nelkin (2015) argue that psychopaths cannot express ill-will. Though their arguments differ in their details, all appeal to psychopaths' inability to appreciate the moral significance of their actions. Levy (2007) appeals to the inability of psychopaths to understand that other humans have moral standing or that they are entitled to certain kinds of treatment. Because they do not understand that others have moral standing, they cannot express any attitudes towards this moral standing, nor can they show contempt for other moral patients as such. These kinds of attitudes, according to

5. The qualifier "typically" is intended to exclude negligent actions. We commonly judge agents blameworthy for negligent actions even though it is a matter of contention whether such actions express ill-will. See, e.g., Sher (2009) for extended discussion.

6. The intuitive sense in which ill-will is required for moral blameworthiness is most likely reflected in the requirement that an offender possess mens rea, or a guilty mind, in order to be legally culpable. Reflection on mens rea may provide a rough idea of the kind of ill-will that is of interest here, but I do not mean to suggest that the two are equivalent (nor that moral blameworthiness and legal culpability are equivalent). 
Levy, are required for the expression of ill-will. Shoemaker (2011) argues along similar lines-because psychopaths are not aware that other beings are entitled to moral consideration, they cannot show genuine contempt for them when they act. While psychopaths may fail to respect their victims, Shoemaker writes, they cannot disrespect them, and the latter is required for ill-will.7 Nelkin (2015) similarly distinguishes between "insensitivity" and "indifference" to moral considerations. She attributes insensitivity to the psychopath, but argues that ill-will requires indifference; since psychopaths are unaware of the moral entitlements of others, they are insensitive to them but cannot be indifferent.

The parties to this debate agree that, in order to be blameworthy, psychopaths must be able to express ill-will by acting. ${ }^{8}$ They further agree, at least to a significant extent, as to what kinds of attitudes psychopaths can express - they can express attitudes towards harm or towards the well-being of others, but cannot express attitudes towards the moral standing or entitlements of others. The disagreement therefore seems to center on what kinds of attitudes count as ill-will. When a philosophical debate dead-ends in an apparently semantic disagreement such as this one, we have some reason to fear that it has reached an impasse; see, e.g., the historical impasse over fetal personhood as the dominant question in determining the permissibility of abortion, and subsequent attempts to break the impasse by moving beyond questions of personhood (Thomson 1971; Marquis 1989).

I argue shortly that the disagreement over ill-will is not merely a semantic one; instead, it reflects a substantive underlying disagreement about which features of actions are wrong-making. The way to make progress, I will argue, is by exposing and addressing this underlying disagreement, rather than by aban-

7. I gloss over one complication here: It is common in discussions of psychopathy to distinguish between various senses of "responsibility", and Shoemaker's main concern is to show that psychopaths are not responsible in the "accountability" sense. When I use the terms "morally responsible" or "blameworthy", I refer to responsibility and blameworthiness in their fullest sense-in Shoemaker's terminology, in the accountability sense. This is the kind of responsibility generally taken to be relevant to retributive punishment-it determines whether agents may be held accountable for their actions - as well as the kind of responsibility central to the disagreement described here.

8. An anonymous reviewer points out that the question of whether psychopaths are blameworthy need not turn on whether they express ill-will, given that agents can apparently be blameworthy for negligent actions without ill-will. The possibility that psychopaths are blameworthy because of negligence rather than ill-will has not, to my knowledge, been discussed in the literature. The reason for this, I suspect, is that negligence only seems to ground blameworthiness when it represents a voluntary failure to manage one's beliefs properly. Psychopathy is apparently not a voluntary condition. Furthermore, psychopaths' lack of concern for moral reasons is a deeply ingrained feature of their worldview, rather than a "mistake" which they would voluntarily correct upon reflection (see, e.g., Maibom 2014 for discussion). These features of psychopathy suggest that psychopathic bad actions are not properly explained as instances of negligence, and that the question we should ask is whether they can instead be attributed to ill-will. 
doning the question of ill-will altogether. It will first be helpful to say a bit more about what I take ill-will to represent, which will set the stage for my diagnosis of the underlying disagreement; it will also be helpful to briefly discuss the rhetorical role played by demands in the existing ill-will literature, which will help to establish that the debate is currently at an impasse.

The intuitive characterization of ill-will which I offered earlier provides a starting point for our inquiry: Ill-will is a kind of bad attitude of the sort that renders agents apt for blame when it is present, and excused from blame when it is absent. We may be tempted to follow Hume and identify ill-will with moral vice more generally, ${ }^{9}$ but this is likely to be unacceptable to some participants in this debate-Levy and Shoemaker, in particular, concede that psychopaths display their moral vices when they act, but not that they express ill-will.

We can refine our picture of ill-will by looking at the way in which the participants in this debate have discussed it. Talbert writes of ill-will as representing a "morally significant perspective" (2008: 532), and suggests that the question of ill-will turns on whether there is "a kind of meaning" behind the actions of psychopaths (2014: 293). Levy suggests that the expression of ill-will requires that psychopaths be able to "grasp the distinctive nature and significance" of the "wrongness" of their actions (2007: 132); only then would they be able to "express contempt for others or for morality" (2007: 135).

These remarks, along with the intuitive characterization of ill-will offered above, suggest the following: The distinctive attitudes that constitute ill-will are attitudes towards the features of actions that make them wrong. It is once again helpful to consider stereotypical cases of exculpation. Suppose that a small child kills his younger sibling by imitating an act of violence seen on television; suppose that he does not understand that death is permanent. We are likely to excuse this child - or attribute to him a greatly diminished degree of blameworthinesson the grounds that his action does not express ill-will. Because he does not understand that death is permanent, he does not really understand its badness; he therefore lacks a grasp of the "nature and significance" of his action, and he does not express significant "contempt" either for his sibling or for morality. His action does not express the judgment that the permanent annihilation of his sibling is an acceptable or desirable outcome, and thus it does not reflect a "morally significant perspective", nor does it have "meaning" as a declaration that his sibling's continued existence is unimportant.

What seems to be important in this case is that the child does not understand the nature of death, and thus is not aware of the features that make his action wrong; as such, he does not express any objectionable attitudes by acting. In

9. See, e.g. A Treatise of Human Nature, Book II, Part III, Section II. Though Hume does not write of "ill-will", he apparently means to suggest that blameworthiness is the result of moral vices being reflected in an agent's actions. 
contrast, an agent who is aware of the features which make his action wrong, but who acts irrespective of this awareness, does demonstrate a "morally significant perspective", and his action does have moral "meaning" - it represents the judgment that the morally significant features of an action are not in fact significant, and thus shows "contempt" towards morality. ${ }^{10}$

The idea that awareness of the wrong-making features of one's actions is crucial to blameworthiness has been defended before, by Nomy Arpaly (2003; 2006) and in a modified form by Arpaly and Timothy Schroeder (2014). More precisely, Arpaly's view is that a failure to respond appropriately to the actual wrong-making features of actions - that is, a failure to be deterred by themis sufficient for blameworthiness. Levy explicitly rejects this view-in fact, one goal of his (2007) paper is to show that this account of blameworthiness is false, as he takes it to imply that psychopaths are blameworthy. Yet Levy also notes that the view can be interpreted in such a way as to allow that psychopaths are not blameworthy: We could understand the failure to respond appropriately to the wrong-making features to require an understanding of the moral status of others. Levy dismisses this alternative understanding of Arpaly's view on the grounds that, on this understanding, there would be nothing "distinctive" about it (2007: 135).

Whether there would in fact be anything distinctive about this variant is not important here. What is important is that the general view-on which illwill consists in an inappropriate attitude towards the wrong-making features of actions - is compatible both with the conclusion that psychopaths express illwill and with the conclusion that they do not. Levy's brief remarks foreshadow the diagnosis which I provide in the next section. The impasse over ill-will, I argue, results from a disagreement over which features of actions are wrongmaking: Are they features like harmfulness, of which the psychopath is aware? Or might they be another kind of feature-a kind of feature the awareness of which requires a grasp of moral concepts?

It is important to note that the feature-centered account of ill-will being discussed here is at least superficially at odds with the accounts offered by some participants in this debate. ${ }^{11}$ Michael McKenna (2012) and Shoemaker (2015),

10. To be clear: The suggestion here is not that an agent must know that certain features of his action make it wrong in order to express ill-will. Rather, the suggestion is that he must know about the presence of the features that do in fact make it wrong. So if feature $\mathrm{F}$ is wrong-making, the agent must know that feature $\mathrm{F}$ is present in order to express ill-will; he need not know that feature $\mathrm{F}$ is wrong-making. To require that an agent know that certain features of his action make it wrong would represent a very stringent requirement for ill-will; it would be equivalent to requiring that an agent know that his action is wrong in order to be blameworthy. This view has been defended (see, e.g., Haji 1998) and would most likely imply that psychopaths cannot express ill-will, but it is not one of the views at issue in this paper.

11. Many thanks to an anonymous reviewer for making clear the need to discuss this. 
for example, have both offered what might be described as "other-centered" accounts, on which ill-will consists in morally objectionable attitudes towards others rather than towards features of actions. ${ }^{12}$ It may seem that these are very different kinds of attitudes. Imagine that the small child from the previous example kills his sibling because he deeply hates him. The objectionable attitude which he displays might be better understood as an attitude towards his sibling rather than towards any features of his actions; if the child strikes us as at least somewhat blameworthy, this might be taken as evidence that it is our attitudes towards others rather than our attitudes towards features of actions that are constitutive of ill-will.

But I think that our attitudes towards others and our attitudes towards the features of our actions are more closely linked than they might at first appear. An action which displays an objectionable attitude of the former kind generally displays an objectionable attitude of the latter kind as well, and vice versa. By knowingly acting in a way that harms someone else, I display both that I have insufficient concern for that person and that I have insufficient concern for the fact that my action will harm that person. This holds true even in the case of the child who kills his sibling, for, while he might not be aware of all of the morallysignificant features of his action, he is presumably aware of at least some of them, and presumably does show attitudes towards the features of which he is aware. He may know, for instance, that people do not like to have violence inflicted upon them, in which case his action displays indifference to whether he violates his sibling's preferences. If we attribute ill-will to this child, it is not immediately clear whether this ill-will consists in the child's attitudes towards his sibling or in his attitudes towards the features of his action. If we stipulate that the child is so young that he is unaware of any of the morally-significant features of killing his sibling, then the killing seems less like an action and more like a behavior of the sort that a non-rational animal could exhibit; it also seems much less plausible as a display of genuine ill-will.

It is often unclear whether the participants in the debate over ill-will mean to assume a feature-centered or other-centered account. Talbert's (2014) discussion is particularly illustrative: He holds that psychopaths can express ill-will, because their actions can express judgments of the following form: "The fact that this action will injure you is no reason to refrain from it" (2014: 281). Does this judgment express indifference towards the fact that the action will cause injury, or indifference towards the recipient of that injury? My take is that it expresses both, and that even if these two attitudes are distinct in principle, for practical purposes they cannot be disentangled. If I fail to care about causing you injury,

12. In Shoemaker's case, as before, the ill-will in question is the kind required for accountability. 
then my concern for you is deficient in at least one important way. And insofar as my concern for you is deficient, I will be insufficiently concerned that my actions affect you adversely.

I return briefly to other-centered accounts of ill-will in the next section, ultimately arguing that our efforts to evaluate psychopaths on these accounts are complicated by the same underlying problem as our efforts to evaluate them on feature-centered accounts. Because feature-centered accounts allow for this underlying problem to be described more clearly, however, I assume an account of this kind for the remainder of this section and for most of the next.

There is one final order of business before moving on, which is to discuss a significant secondary debate which often features prominently in discussions of the ill-will question. Gary Watson (1996) argues that agents are blameworthy only when they are appropriate targets for certain kinds of demands. ${ }^{13}$ Following Watson, it may seem that we can gain insight into the status of psychopaths by asking which sorts of demands we can make of them. Call this the demand question.

The demand question is conceptually distinct from the ill-will question, and is sometimes treated as representing a separate debate. ${ }^{14}$ Even when the demand question is raised in the context of the ill-will debate, it is sometimes unclear how or even whether it is meant to be connected to ill-will. Levy (2007) and Shoemaker (2011) argue that psychopaths are not apt targets for moral demands, on the grounds that they cannot respond to moral considerations and thus cannot be swayed by moral discourse. Talbert (2008) argues that they are apt targets for moral demands, noting that the aptness of a demand need not depend on whether the recipient is likely to respond to it; demands might serve a variety of purposes apart from changing the behavior of those to whom they are directed. This disagreement-which centers on the general conditions under which demands are appropriate-seems to be independent of the ill-will question.

But we can also understand the demand question in such a way that is plausibly related to the ill-will question. Nelkin (2015), following Watson, notes that psychopaths can refrain from performing particular bad actions when motivated to do so; thus, it would seem, demands to act properly are potentially apt. But, Nelkin argues, "there is good reason to think that the demands [relevant to responsibility] are not of this type. Rather, the demands in question are demands to act in such ways for certain reasons" (2015: 376). Because psychopaths lack the

13. More precisely, Watson argues that agents are not blameworthy in the fullest sense unless they are apt targets of such demands. I continue to use "blameworthiness" to refer to the fullest sense of blameworthiness, such as is required to justify retributive punishment.

14. Watson (2011) apparently regards the debates as separable: He allows that psychopaths express ill-will but denies that they are blameworthy, on the grounds that they are not subject to the right kinds of demands. 
concepts required to understand moral reasons, they cannot be motivated by them; thus, demands that they be so motivated are inapt.

In this way, Nelkin suggests, the ill-will question and the demand question are linked - on her view, the same fundamental incapacity to understand moral considerations renders the psychopath both unable to express ill-will and unable to respond to demands of the relevant type. But while there is a plausible connection between the two questions, the appeal to demands seems unlikely to assist us in answering the ill-will question. The problem is that Nelkin's answer to the demand question depends on a certain view of what the right reasons are. A defender of Talbert's view is likely to adopt a different view of the right reasons, and thus to answer the demand question differently.

Nelkin argues that the expression of ill-will requires knowledge of the moral standing of others. She also believes that the demands relevant to blameworthiness are demands to act well for the right reasons, where the right reasons are, presumably, connected to the fact that others have moral standing. But suppose that we take a different view of ill-will-suppose that, like Talbert, we believe that ill-will merely requires the judgment that harm or injury to others is not reason-giving. We, like Nelkin, want to know whether psychopaths can act well for the right reasons. But what are the right reasons, given our view of ill-will? Presumably, the right reasons are those that we would respond to if our will were good rather than bad. This means that the right reason not to assault someone is the fact that it harms or injures him. But psychopaths can respond to reasons of this kind, at least in principle - they do not lack the relevant concepts, as is the case with reasons related to moral standing - and it seems that it is apt for us to demand that they do so.

So whether or not psychopaths satisfy the demand requirement depends on which demands, precisely, are relevant to responsibility. This in turn depends on which reasons are the right reasons for action, which depends on which features make actions right or wrong. Thus the demand question seems unlikely to provide further insight into the ill-will question, because the answers to both depend on which features of actions are right- or wrong-making. In the next section, I turn to a more detailed discussion of this underlying question.

\section{Which Features are Wrong-Making?}

The question of which features are wrong-making is more difficult than it may at first appear. Even when a given set of normative assumptions is held fixed, there may be multiple features which can plausibly be identified as wrong-making.

It will be easiest to illustrate the problem of interest with a case involving a non-psychopathic agent. Suppose that it is always wrong to kill a person, and 
that it is always right to prevent a person from being killed (at least when this can be done without killing). ${ }^{15}$ Suppose also that a being is a person in virtue of possessing certain psychological properties, such as feelings and self-awareness.

Clinic Bomber: George is deeply concerned with the well-being of persons, and is strongly motivated to save persons from being killed. Because he believes that fetuses are persons, he believes that he can save persons by preventing abortions. Accordingly, he places a small bomb in an abortion clinic and detonates it at a time when he knows the clinic will be unoccupied. The resulting damage to the facility, which is located in an area with limited access to abortion, forces it to close for several weeks and prevents a number of abortions which would otherwise have taken place.

George originally became convinced that fetuses were persons when he read a description of their biology. A fetus has a complete and unique human genome, and this, George thinks, endows it with personhood. This belief is false - a being actually requires certain psychological properties in order to be a person - but George came to have it by reasoning responsibly and without self-deception. Fetuses do not in fact have the required psychological properties, and so George's action does not actually save any persons.

Assume that good will is the opposite of ill-will; an agent displays good will when his action reflects appropriate attitudes towards the features of actions that make them right. Does George's action reflect good will? This is a potentially surprising question, perhaps because we often attribute ulterior motives or epistemic irresponsibility to those who bomb abortion clinics. But these complicating factors have been ruled out in Clinic Bomber, and there seems to be a strong case that George's action does reflect good will. ${ }^{16}$

George performs an action that is not, in fact, morally good. But it does re-

15. This set of normative facts is unrealistically simple, but the simplification should not adversely affect the following discussion.

16. As an anonymous reviewer points out, this thought experiment depends on the assumption that George really could come to hold the beliefs that he does without epistemic irresponsibility; if the beliefs themselves strike us as highly implausible, we might wonder whether this is the case. While I cannot offer an extended defense here, I think we have good reason to accept this assumption as a legitimate one. Even if we think that any agent would reject these beliefs after examining them sincerely, we can imagine that George has never examined his beliefs because he has never had any evidence that they ought to be examined. Rosen (2004) argues that this phenomenon - in which agents reasonably hold unreasonable beliefs because they have never had reason to examine them-is common. For present purposes, it is sufficient that this phenomenon be possible. 
flect a deep concern for the well-being of persons, as well as an intention to save them. As stipulated, actions that save persons (without killing) are morally right, and thus George seems to be acting on a good intention. And on an intuitive level, it seems that the motivation to save persons is one that is morally desirable or simply good. We might think that George's failure to act well is attributable to a non-moral mistake that does not diminish the quality of the will that he expresses. If a would-be rescuer went through heroic efforts to save a lifeboat that she believed was full of people, we would likely judge her action to express good will even if the lifeboat turned out to be unoccupied. Perhaps we should judge George's action similarly.

On the other hand, there also seems to be a strong case that George's action does not express good will. For while George wants to save persons, he does not really know what persons are. Persons matter morally, but we might think that this is because of their psychological properties. Imagine having an argument with George about the question of whether fetuses are persons. George asserts that fetuses are persons in virtue of their genetic properties; by way of response, we are likely to argue that genetic properties cannot be the basis for personhood because there simply isn't anything morally important about them. If this rhetorical strategy seems reasonable, this suggests that we are inclined to think that it is the personhood-conferring properties - rather than personhood itself - that are actually morally important. Since George's action does not express any attitudes towards these personhood-conferring properties, we might conclude that the quality of will expressed by his action is neutral at best.

My aim is not to adjudicate between these two reactions to Clinic Bomber, but rather to show that both reactions are prima facie plausible. Certain considerations should pull us towards the conclusion that George expresses a good will when he acts, while others should pull us towards the conclusion that he does not. This case is intended to illustrate the relevant sense in which there sometimes seem to be multiple features, at multiple "levels", which can plausibly be described as right-making or wrong-making.

Given the normative assumptions made in Clinic Bomber, there seem to be at least two features which one could plausibly identify as making a given instance of saving persons right, namely:

The higher-level feature: This action saves persons.

The lower-level feature: This action saves beings with psychological properties $\mathrm{X}, \mathrm{Y}$, and $\mathrm{Z}$.

I regard these as two distinct features of the action, because I interpret them as representing two non-identical properties. While I stipulated that a being is a person in virtue of possessing certain psychological properties, I did not mean to 
assume that personhood is identical to having those properties. In fact, I believe that it is not-our standard concept of "personhood" seems to be a normatively "thick" one. To judge that a being is a person is not only to ascribe to it certain descriptive properties, but to attribute to it moral standing and an entitlement to certain kinds of treatment.

The fact that we conceptually distinguish between personhood and the possession of certain psychological properties is admittedly not sufficient to establish that these really are distinct features; it might turn out that these represent the same feature under different conceptualizations. In either case, it should be agreed that the intention or desire $<$ to save/kill persons $>$ is a distinct attitude from the intention or desire <to save/kill beings with psychological properties $X, Y$, and $Z>$. Readers who prefer to treat these as attitudes towards two conceptualizations of the same feature are free to do so. In the following pages, I will discuss the question of which "feature" is genuinely wrong-making; but this can be substituted with the question of which conceptualization of the (single) wrongmaking feature is relevant to ill-will. I briefly return, in the conclusion, to discuss how questions of conceptualization might be relevant to breaking the impasse. ${ }^{17}$

Proceeding under the assumption that these are two distinct features, I take it that when the higher-level feature is present, it is present in virtue of the lowerlevel feature's being present, but not vice-versa. A given action saves a person in virtue of saving a being with certain psychological properties, but an action does not save a being with certain psychological properties in virtue of saving a person. Because of this one-way in-virtue-of relationship, I describe the features as occupying different "levels." I further take it that both features "make" the action right, at least in some weak sense; at the very least, both are correct answers to the question of why the action is right. But this is not, for our purposes, sufficient for them to be right-making.

The right- and wrong-making features are of interest to us because they are the features of which an agent must be aware in order to express good- or ill-will. An agent who displays a certain attitude towards the right- or wrongmaking features, recall, is one who has taken a "morally significant perspective", and whose actions possess a certain "meaning". Some features of our actions clearly do not qualify. The fact that the victim will stop moving after being killed seems to represent a side-effect of the killing, rather than the feature that makes it wrong; a small child who knows about the stillness but not about the other features of killing does not seem to express a strongly objectionable attitude by acting and does not seem to be significantly blameworthy. Other features seem

17. One might object to my description of Clinic Bomber by claiming that George does not really want to save persons-after all, the entities he wants to save are not in fact persons. But we should at least agree that George does want $<$ to save persons $>$. Many thanks to Julia Markovits for suggesting this objection. 
to be clearly irrelevant even though they do arguably make an action right or wrong in some sense. The fact that my action causes certain neural events may make it the case that it constitutes the causing of pain, which may make it wrong. But it seems clear that there is nothing morally significant about the neural states themselves, except insofar as they cause or constitute a painful experience; nor do I seem to express anything morally significant if I desire either to cause or to prevent certain brain states, unless I also know that they are associated with pain.

The question that we face when evaluating George is which of the features of a given instance of saving persons is right-making in the required sense. Which feature is such that an agent's caring about it represents a "morally significant perspective"? And the problem is that there seems to be a plausible case to be made for both. On the one hand, our attitudes towards persons seem to be morally significant. On the other hand, we might wonder whether their significance ultimately derives from our attitudes towards the personhood-conferring properties, rather than towards personhood itself.

Now consider the case of a psychopathic agent. Suppose, as before, that an action is wrong if it kills a person; continue to suppose that a being is a person in virtue of possessing certain psychological properties.

Robbery: Newman is a psychopath. His general intelligence is average, and he has a fairly good understanding of the minds of other humans. He understands that other humans have feelings, a persistent sense of self, and all of the other psychological properties that confer personhood. Newman does not, however, understand that other humans have rights or moral standing, nor that they are entitled to be treated in certain ways; therefore, he does not understand that other humans are persons. Newman robs a convenience store and intentionally kills the clerk in order to avoid leaving behind any witnesses; he knows that in so doing he kills a being with the personhood-conferring psychological properties, but not that he kills a person.

To assess Newman for blame, we must ask whether he displayed ill-will by acting. This in turn will require us to ask whether he displayed an inappropriate attitude towards the features which made his action wrong. And there seem to be two plausible answers, because there are two plausible wrong-making features:

The higher-level feature: This action kills a person.

The lower-level feature: This action kills a being with psychological properties $\mathrm{X}, \mathrm{Y}$, and Z. 
Newman does not know that he kills a person. So, if killing a person is what makes the action wrong, Newman is unaware of the wrong-making feature of his action and does not express ill-will. However, Newman does know that he kills a being with all of the properties which do, in fact, confer personhood. If killing a being with these properties is what makes the action wrong, then Newman is aware of the wrong-making feature of his action, does express an inappropriate attitude towards this feature, and thereby does express ill-will.

My contention is that the impasse over the ill-will question reflects an implicit disagreement over which features of actions are wrong-making. Levy and Nelkin both point towards the psychopath's lack of awareness that others have moral standing; this lack of awareness, Levy writes, prevents the psychopath from "grasp[ing] the distinctive nature and significance" of the "wrongness" of his actions (2007: 135). At work here seems to be the implicit identification of the wrong-making features with harms or other wrongs inflicted on beings with moral standing - that is, on persons. Because psychopaths have no conception of moral standing and a fortiori no conception of personhood, they cannot judge that any kind of treatment of persons is acceptable or unacceptable; as such, they cannot express any attitudes towards the wrong-making features of their actions and cannot express ill-will. ${ }^{18}$

Talbert agrees that psychopaths do not know that others have moral standing. But on his view, this does not preclude them from expressing ill-will. They can intend harm, and can judge that harm not to be reason-giving. These attitudes, according to Talbert, are sufficient for ill-will. This argument seems to reflect the implicit identification of the wrong-making features of the psychopath's actions with their harmfulness ${ }^{19}$ - because the psychopath is aware of the wrong-making features and does express inappropriate attitudes towards them, he does express ill-will.

If the impasse over the ill-will question is due to an implicit disagreement over which features are wrong-making, why has this disagreement thus far remained implicit? The answer is that the difficulty of identifying the true wrongmaking features has not, to my knowledge, previously been appreciated. Others have discussed senses in which either moral explanation or moral reasons seem to have a multi-level structure. Pekka Väyrynen (2013) distinguishes between bearer explanations, which appeal to the features of actions in virtue of which

18. Many of the most important bad actions performed by psychopaths will involve wrongs inflicted on persons, but if we prefer, we can substitute the term "moral patient" for "person" - I assume that persons are a kind of moral patient, and that psychopaths cannot appreciate that they harm moral patients more generally. I mean to clarify that my diagnosis of the difficulty is not limited only to those psychopathic wrongs inflicted on persons; it should also apply to wrongs inflicted on, for instance, animals.

19. I assume that killing generally involves the infliction of a kind of harm. 
they have their deontic properties, and source explanations, which offer an accounting of why an action has a certain deontic status in virtue of having certain bearers. Daniel Star (2011; 2015) distinguishes between the moral reasons typically invoked in folk moralities and those typically appealed to in philosophical theorizing, characterizing them as features at different levels.

But the multi-level structure I describe here is quite different from these. I have proposed that there are features at multiple levels, each of which has a plausible claim to be wrong-making. The distinction between lower- and higherlevel features is not the same as that between bearer and source explanations; in Väyrynen's terminology, I have described two features each of which has a plausible claim to be a bearer of normativity, and the difficulty consists in identifying which one is the true bearer. Nor do the lower- and higher-level features have more than a superficial connection to Star's lower- and higher-level reasons: Both facts about personhood and facts about personhood-conferring features are generally accessible to the folk, so long as they are non-psychopathic. ${ }^{20}$

The fact that both kinds of features are generally accessible to normal agents is one reason that the difficulty described here has not previously been appreciated. The agents that we normally evaluate for blame are either aware of both the higher- and lower-level features of their actions, or they are aware of neither of them. A typical agent who knowingly commits murder is aware both that he kills a person and that he kills a being with the relevant psychological properties; a typical agent who kills someone inadvertently is aware neither that he kills a person nor that he kills a being with the relevant psychological properties. Most cases, therefore, do not require us to distinguish between the higher- and lowerlevel features. It is only in very unusual cases that an agent is aware of one of these features but ignorant of the other. Psychopaths present one such case, ${ }^{21}$ and in order to evaluate them, we are forced to take a position, at least implicitly, as to which features make actions bad.

Because the difficulty in determining which features are wrong-making has not previously been appreciated, a major underlying cause of the disagreement

20. More precisely, the two-level structure that I propose allows for the possibility that both the lower- and higher-level features are accessible to the folk. As I discuss at the end of this section, my model is compatible with the possibility that the personhood-conferring properties might turn out to be relatively obscure non-psychological properties, and these would not necessarily be accessible to the folk. In any case, the relationship between the two levels is not supposed to be an epistemic relationship on my model, which distinguishes it from Star's.

21. Agents with certain sets of moral beliefs, like George, present another example, though cases of this kind have not attracted significant attention in the literature. If cases like Clinic Bomber were widely discussed, however, I would expect a pattern of disagreement similar to the one over psychopathy - some of us would implicitly assume that saving persons makes an action good, and conclude that George expresses good will, while some of us would implicitly assume that saving a being with personhood-conferring properties makes an action good, and conclude that George's quality of will is neutral at best. 
over ill-will has been obscured. Hence the impasse. Now that the cause of the impasse has been revealed, we can go about breaking it; in the final section, I discuss several approaches to doing so.

Before proceeding, two worries. The first worry: As noted in the previous section, it is sometimes unclear whether the accounts of ill-will at work in discussions of psychopathy are meant to be feature-centered or other-centered. Will the diagnosis I describe here still explain the impasse if we understand the disagreement over ill-will to center on a psychopath's attitudes towards others, rather than on his attitudes towards the features of his actions?

I think that it will. Consider a particular attitude that we might have towards others; say, concern for them. The precise content of this attitude will depend on precisely what we take others to be. If we take others to be persons-beings with certain rights and entitlements, etc. - then we are concerned for others qua persons. If, on the other hand, we merely take others to be entities with certain properties-psychological properties X, Y, and Z, for example-then our concern for others will amount to concern for beings with these properties. That there are two different attitudes which might correctly be described as concern for others is likely to be non-obvious, since most agents who care about others care both about persons and about beings with the personhood-conferring properties. But in cases like Clinic Bomber, these attitudes can come apart. George expresses concern for others qua persons when he acts, but not concern for others qua possessors of properties $\mathrm{X}, \mathrm{Y}$, and $\mathrm{Z}$.

These two kinds of attitudes also come apart in the case of the psychopath. Psychopaths know that others have properties X, Y, and Z, and thus can display indifference towards others qua possessors of those properties. But psychopaths do not know that others are persons and thus cannot show indifference towards others qua persons. Whether psychopaths are blameworthy depends on precisely which kind of indifference towards others counts as ill-will.

I take it that the underlying problem here is nearly equivalent to the one described earlier in this section. On a feature-centered account of ill-will, the question is precisely which features of actions are wrong-making in such a way that our attitudes towards them represent a morally significant perspective. Is the moral significance of actions due to their harming persons? Or to their harming beings with the personhood-conferring properties? On an other-centered account, the question is precisely how we need to conceive of others for our attitudes towards them to be morally significant; to answer this question would seem to require us to know precisely what it is about others that accounts for their moral importance. Are others morally important because they are persons? Or are they morally important because they possess the personhood-conferring properties? Insofar as the wrong-making features of actions concern their effects on others, it seems as though both feature-centered and other-centered accounts 
of ill-will will require us to answer the same question before we can evaluate psychopaths. Is it persons - and the effects of our actions on persons - that matter morally? Or is it beings with the personhood-conferring properties-and the effects of our actions on such beings - that matter? ${ }^{22}$

The second worry: Is the difficulty I describe here, and thus my diagnosis of the cause of the impasse, merely the result of the particular normative assumptions made in Clinic Bomber and Robbery? Different normative assumptions may not produce the same problem. Suppose, for instance, that hedonistic utilitarianism is true. Persons play no role in such a theory; the only thing that matters is the balance of happiness over unhappiness, regardless of whether the experiencers are persons or not. It is difficult to see how this normative theory could allow for any ambiguity as to which features are right- and wrong-making; the only plausible right- or wrong-making features would be an action's effects on happiness and unhappiness.

But it is not necessary, for my purposes, that the difficulty arise for all possible sets of normative assumptions. To be responsible for the impasse over the ill-will question, it need only arise for the normative assumptions that are typically made in discussions of psychopathy. These discussions generally do not make explicit normative assumptions; the reason, I suspect, is that the question of whether psychopaths can be blameworthy is presumed to be independent of which normative theory is correct. ${ }^{23}$ When these discussions do require firstorder normative claims to be made-when, for example, they need to mention certain actions as examples of psychopathic wrongdoing - the claims seem to be chosen with an aim towards being ecumenical and pretheoretically plausible. Robbery, assault, and murder, for instance, may be held out as examples of wrong actions.

The claim that it is wrong to treat persons in certain ways is itself fairly ecumenical, and likely to be deeply ingrained in our pretheoretical moral thinking; it is therefore very likely to be among the normative background assumptions

22. The situation is more complicated for more complex accounts of ill-will. For example, Shoemaker (2015) requires that an agent be capable of responding to others empathetically in order for his actions to express ill-will. Though I have described this as an other-centered account, the requirement that an agent have the capacity for empathy makes a significant difference. On the assumption that psychopaths do not have this capacity, Shoemaker's (2015) account allows us to conclude that they cannot express ill-will, without requiring us to take a position either as to which features of actions make them wrong or as to what it is about others that makes them morally important. So I do not maintain that all accounts of ill-will - or even all other-centered accountsrequire us to answer these questions before we can evaluate psychopaths. But it is important to underscore that it is Shoemaker's empathy requirement-and not the emphasis on attitudes towards others, rather than towards the features of actions - that makes the difference.

23. On at least one approach to the difficulty described in this paper, it will turn out that the responsibility status of psychopaths is dependent on which normative theory is correct; see the final section for discussion. 
present in most discussions of psychopathy. Significantly, the personhoodconferring properties need not be psychological for the problem to arise. As long as it is wrong to treat persons in certain ways, and as long as there are some properties in virtue of which a being is a person, then there will be an open question as to whether the moral significance of actions derives from their effects on persons or from their effects on the personhood-conferring properties.

The difficulty also seems likely to arise for at least some sets of normative assumptions that do not invoke personhood. Suppose, for instance, that it is wrong to violate anyone's rights, and that one right possessed by everyone is the right not to be harmed. Suppose that I harm someone. Which feature of my action makes it wrong? On the one hand, the violation of rights seems to be intrinsically bad, so perhaps this is the wrong-making feature. On the other hand, perhaps the harmfulness of my action is wrong-making. After all, it seems as though there must be something bad about harm which explains why we have the right not to be harmed, as opposed to, say, the right not to be offended. As with the previous examples, we would need to identify which of these features is genuinely wrong-making in order to evaluate psychopaths. Psychopaths are likely to lack the concept of rights, and thus to be unable to show any attitudes towards them; but, as noted, they do have a good understanding of harm.

So any set of normative assumptions on which it is wrong to violate rights, or to treat persons in certain ways, will admit of the ambiguity-so long as there is also some explanation as to why certain rights exist, or as to why certain entities are persons. These seem likely to be a part of the background assumptions that guide our pretheoretical reasoning about morality, and can also be expected to be assumed, at least in the background, in most philosophical discussions of psychopathy.

\section{Breaking the Impasse}

The impasse over the question of whether psychopaths can express ill-will is due to an implicit disagreement as to which features of actions are wrong-making. To break the impasse, we should seek to resolve this underlying disagreement. I do not endorse any particular resolution in this paper, but instead conclude by discussing three possible approaches to the problem.

The first option is to approach the question as a first-order normative one. We are interested in which features of actions are wrong-making; this, at least on its face, would seem to be a question that we could answer by discovering the correct normative theory. In presenting the cases in the last section, I tried to show how a given set of normative assumptions could identify two plausible candidate wrong-making features. But one might think that this is because the 
normative assumptions I made were too imprecise. Perhaps the correct normative theory, if known and described with sufficient precision, would tell us all we need to know-it would identify either the mistreatment of persons or the mistreatment of beings with personhood-conferring properties as wrong-making.

It is worth noting that this approach would require us to accept the implication that the blameworthiness of psychopaths depends on which normative theory is correct. If the correct normative theory identifies the lower-level features as wrong-making, then psychopaths are blameworthy; if it identifies the higher-level features, then they are not. As noted, in the past it has apparently been assumed that the details of the correct normative theory are irrelevant to the responsibility status of the psychopath. If we approach the difficulty as a first-order normative problem, then we will need to abandon this assumption.

The second option is to approach the question as one which concerns the correct conceptualization of the bad. If we think that the putative "features" discussed in the previous section are not really distinct, but merely different conceptualizations of the same feature, then presumably this is the approach that we must take. Arpaly and Schroeder (2014) require that attitudes towards the actual good or bad be under the "correct" conceptualization in order to count as good- or ill-will. Their aim is to exclude attitudes towards the good and bad de dicto, as well as certain attitudes that are clearly irrelevant to the quality of an agent's will (such as an attitude towards pain conceptualized as certain neural events). ${ }^{24}$

Perhaps a similar approach could help us resolve the difficulty underlying the ill-will question. If we can determine which conceptualization is the "correct" or relevant one-the conceptualization of an act as killing a person, or the conceptualization of an act as killing a being with the actual personhood-conferring properties-we could determine which attitudes count as ill-will. It is worth noting that it is not entirely clear how we should go about answering this questionhow can we determine which conceptualizations are the relevant ones? Arpaly and Schroeder's view is that the correct conceptualization is identified by the correct normative theory. If the relevant conceptualization does derive from the correct normative theory, then this approach will also require us to know the correct normative theory before we can evaluate psychopaths.

The final option is to approach the question as one which concerns normative explanation. I have characterized the features of interest as those that make actions wrong, but we might alternatively understand them as the features that explain why actions are wrong. If we can identify which features explain the wrongness of actions, we will know which features an agent must be aware of in order to express ill-will.

24. (2014: 163-167). 
At this juncture, the nature of normative explanation remains fairly mysterious. Väyrynen (2013) offers a useful summary of the situation. Many of us share the strong intuition that "actions ... have their normative and evaluative properties in virtue of their non-normative, non-evaluative properties" (Väyrynen 2013: 155). But the nature of this in-virtue-of relation is highly controversial. One possibility is that it is a grounding relation, although Väyrynen offers some reasons to be skeptical of this. David Enoch (2011) suggests another possibility: there are normative laws, analogous to the laws of nature, which connect certain nonnormative properties to certain normative ones. There are many other possible ways of filling in the details of the in-virtue-of relationship, and it will not be possible to survey them here. ${ }^{25}$

If we did understand the nature of this relationship, however, it might enable us to identify which kinds of features are relevant to ill-will. The relationship, recall, has two relata-the deontic status of the action on one side, and the features of the action which explain that status on the other. And particular accounts of this relationship might place constraints on which features of actions can plausibly serve as relata.

I offer only the barest sketch here of how this might work, but it should at least demonstrate how it is possible, in principle, to make progress on this question by clarifying the nature of moral explanation. Suppose that something like Enoch's view is correct, and that there are normative laws which connect certain non-normative properties to certain normative ones. The proper relata for the normative in-virtue-of relationship must also be proper relata for these normative laws. One might think that the higher-level features are more plausible relata for these laws, and thus more likely to be the features which explain the wrongness of actions. This seems especially likely if there are multiple sets of properties which could confer personhood. Were the personhood-conferring properties the ones that explained why actions were wrong, the normative laws would need to take an awkward, disjunctive property as a relatum-e.g., an action is wrong just in case it harms a being with this set of properties, or that set of properties, or this other set of properties. A law which states that actions are wrong just in case they harm persons is simpler and arguably more plausible.

I leave open the possibility that other accounts of the normative in-virtueof relation might identify the lower-level features as the more plausible relata. The important point is that the correct account of normative explanation could provide us with insight into which kinds of features explain the wrongness of actions, and in turn into which kinds of attitudes are required for ill-will.

Whichever way we approach this problem, it seems that answering the ill-

25. See Stephanie Leary (in press) for a defense of one such account and an informative overview of many others. 
will question will require us to venture into some areas of moral philosophy not typically associated with questions of responsibility. To evaluate psychopaths, we will need to know which features of their actions are wrong-making; this will most likely require us either to know the details of the correct normative theory or to have a better idea of how it is that the features of actions explain their wrongness. Although the proposals described here represent a departure from existing approaches to psychopathy, they also offer us the prospect of progress on a debate which is currently stalled.

\section{Acknowledgements}

Many thanks to Ben Bradley, Scott Looney, Hille Paakkunainen, Preston Werner, and my other colleagues who offered feedback on a version of this paper presented at Syracuse University in Spring 2016. Many thanks also to David Shoemaker, Matthew Talbert, and others who offered feedback on a different version presented at the Gothenburg Responsibility Project's Summer 2016 conference at the University of Gothenburg. Finally, many thanks to the two anonymous referees for Ergo whose constructive comments helped me to polish this paper into its present form.

\section{References}

Arpaly, Nomy (2003). Unprincipled Virtue. Oxford University Press.

Arpaly, Nomy (2006). Merit, Meaning, and Human Bondage: An Essay on Free Will. Princeton University Press.

Arpaly, Nomy and Timothy Schroeder (2014). In Praise of Desire. Oxford University Press.

Borg, Jana Schaich and Walter Sinnott-Armstrong (2013). Do Psychopaths Make Moral Judgments? In Kent Kiehl and Walter Sinnot-Armstrong (Eds.), Handbook on Psychopathy and Law (107-128). Oxford University Press.

Cleckley, Hervey (1964). The Mask of Sanity. The C.V. Mosby Company.

Enoch, David (2011). Taking Morality Seriously: A Defense of Robust Realism. Oxford University Press. https://doi.org/10.1093/acprof:0so/9780199579969.001.0001

Haji, Ishtiyaque (1998). Moral Appraisability: Puzzles, Proposals, and Perplexities. Oxford University Press.

Hare, Robert D. (1993). Without Conscience: The Disturbing World of the Psychopaths among Us. The Guilford Press.

Hume, David (2000). A Treatise of Human Nature. David Fate Norton and Mary J. Norton (Eds.). Oxford University Press.

Kiehl, Kent A. (2008). Without Morals: The Cognitive Neuroscience of Criminal Psychopaths. In Walter Sinnott-Armstrong (Ed.), Moral Psychology, Volume 3: The Neuroscience of Morality: Emotion, Brain Disorders, and Development (119-149). The MIT Press.

Leary, Stephanie (in press). Non-naturalism and Normative Necessities. In Oxford Studies in Metaethics, Volume 12. Oxford University Press. 
Levy, Neil (2007). The Responsibility of the Psychopath Revisited. Philosophy, Psychiatry and Psychology, 14(2), 129-138. https://doi.org/10.1353/ppp.0.0003

Litton, Paul (2008). Responsibility Status of the Psychopath: On Moral Reasoning and Rational Self-Governance. Rutgers Law Journal, 39, 349-392.

Lykken, David T. (2006). Psychopathic Personality: The Scope of the Problem. In Christopher J. Patrick (Ed.), Handbook of Psychopathy (3-13). The Guilford Press.

Maibom, Heidi L. (2008). The Mad, the Bad, and the Psychopath. Neuroethics, 1(3), 167184. https://doi.org/10.1007/s12152-008-9013-9

Maibom, Heidi L. (2014). To Treat a Psychopath. Theoretical Medicine and Bioethics, 35(1), 31-42. https://doi.org/10.1007/s11017-014-9281-9

Marquis, Don (1989). Why Abortion is Immoral. Journal of Philosophy, 86(4), 183-202. https://doi.org/10.2307/2026961

McKenna, Michael (2012). Conversation and Responsibility. Oxford University Press. https://doi.org/10.1093/acprof:0so/9780199740031.001.0001

Nelkin, Dana Kay (2015). Psychopaths, Incorrigible Racists, and the Faces of Responsibility. Ethics, 125(2), 357-390. https://doi.org/10.1086/678372

Rosen, Gideon (2004). Skepticism about Moral Responsibility. Philosophical Perspectives, 18(1), 295-313. https://doi.org/10.1111/j.1520-8583.2004.00030.x

Scott, Russ (2014). Psychopathy - An Evolving and Controversial Construct. Psychiatry, Psychology and Law, 21(5), 687-715. https://doi.org/10.1080/13218719.2014.911056

Sher, George (2009). Who Knew? Responsibility without Awareness. Oxford University Press. https://doi.org/10.1093/acprof:0so/9780195389197.001.0001

Shoemaker, David (2011). Attributability, Answerability, and Accountability: Toward a Wider Theory of Moral Responsibility. Ethics, 121(3), 602-632. https://doi. org/10.1086/659003

Shoemaker, David (2015). Responsibility from the Margins. Oxford University Press. https://doi.org/10.1093/acprof:0so/9780198715672.001.0001

Star, Daniel (2011). Two Levels of Moral Thinking. In Mark Timmons (Ed.), Oxford Studies in Normative Ethics, Volume 1 (75-96). Oxford University Press. https://doi. org/10.1093/acprof:0so/9780199693269.003.0004

Star, Daniel (2015). Knowing Better: Virtue, Deliberation, and Normative Ethics. Oxford University Press. https://doi.org/10.1093/acprof:0so/9780199570416.001.0001

Talbert, Matthew (2008). Blame and Responsiveness to Moral Reasons: Are Psychopaths Blameworthy? Pacific Philosophical Quarterly, 89(4), 516-535. https://doi.org/10.1111/ j.1468-0114.2008.00334.x

Talbert, Matthew (2012). Accountability, Aliens, and Psychopaths: A Reply to Shoemaker. Ethics, 122(3), 562-574. https://doi.org/10.1086/664751

Talbert, Matthew (2014). The Significance of Psychopathic Wrongdoing. In Thomas Schramme (Ed.), Being Amoral: Psychopathy and Moral Incapacity (275-300). The MIT Press.

Thomson, Judith Jarvis (1971). A Defense of Abortion. Philosophy and Public Affairs, 1(1), 47-66. https://doi.org/10.1007/978-1-4615-6561-1_6

Väyrynen, Pekka (2013). Grounding and Normative Explanation. Aristotelian Society Supplementary Volume, 87(1), 155-178. https://doi.org/10.1111/j.1467-8349.2013.00224.x

Watson, Gary (1996). Two Faces of Responsibility. Philosophical Topics, 24(2), 227-248. https://doi.org/10.5840/philtopics199624222

Watson, Gary (2011). The Trouble with Psychopaths. In R. Jay Wallace, Rahul Kumar, 
and Samuel Freeman (Eds.), Reasons and Recognition: Essays on the Philosophy of T.M. Scanlon (307-331). Oxford University Press.

Widiger, Thomas A. (2006). Psychopathy and DSM-IV Psychopathology. In Christopher J. Patrick (Ed.), Handbook of Psychopathy (156-171). The Guilford Press. 